University of Wollongong

Research Online

Faculty of Engineering and Information

Faculty of Engineering and Information

Sciences - Papers: Part A

Sciences

$1-1-2011$

Effect of magnetostatic field on microstructure of 5005 aluminum alloy sheet by roll-casting

Jintao Li

University of Wollongong, j1221@uowmail.edu.au

Guangming Xu

Northeastern University

Jianzhong Cui

Northeastern University, Liaoning

Follow this and additional works at: https://ro.uow.edu.au/eispapers

Part of the Engineering Commons, and the Science and Technology Studies Commons

Research Online is the open access institutional repository for the University of Wollongong. For further information contact the UOW Library: research-pubs@uow.edu.au 


\title{
Effect of magnetostatic field on microstructure of 5005 aluminum alloy sheet by roll-casting
}

\author{
Abstract \\ The roll-casting technology of 5000 series aluminum alloy is one of the difficulties at present. Roll-casting \\ technology was employed in this paper and high quality 5005 aluminum alloy sheets were fabricated \\ successfully under different conditions. The solidification of melt in roll-casting process is the rapid \\ directional solidification. The effect of magnetostatic field on microstructure of 5005 aluminum alloy \\ sheet by roll-casting has been investigated and analyzed. The results indicate that imposing \\ magnetostatic field can refine the grains of 5005 aluminum alloy.

\section{Keywords} \\ alloy, sheet, casting, roll, field, microstructure, magnetostatic, 5005, effect, aluminum \\ Disciplines \\ Engineering | Science and Technology Studies

\section{Publication Details} \\ Li, J., Xu, G. \& Cui, J. (2011). Effect of magnetostatic field on microstructure of 5005 aluminum alloy sheet \\ by roll-casting. Advanced Materials Research, 189-193 4018-4021.
}




\title{
Effect of magnetostatic field on microstructure of 5005 aluminum alloy sheet by roll-casting
}

\author{
Jintao $\mathrm{Li}^{\mathrm{a}}$, Guangming $\mathrm{Xu}^{\mathrm{b}}$ and Jianzhong $\mathrm{Cui}^{\mathrm{C}}$
}

Key Laboratory of Electromagnetic Processing of Materials (Ministry of Education), Northeastern University, Shenyang, Liaoning, 110819, China

ajintaol@foxmail.com, bxu_gm@epm.neu.edu.cn, ${ }^{c}$ jzcui@epm.neu.edu.cn

Keywords: 5005 aluminum alloy, Roll-casting, Magnetostatic field, Refine.

\begin{abstract}
The roll-casting technology of 5000 series aluminum alloy is one of the difficulties at present. Roll-casting technology was employed in this paper and high quality 5005 aluminum alloy sheets were fabricated successfully under different conditions. The solidification of melt in roll-casting process is the rapid directional solidification. The effect of magnetostatic field on microstructure of 5005 aluminum alloy sheet by roll-casting has been investigated and analyzed. The results indicate that imposing magnetostatic field can refine the grains of 5005 aluminum alloy.
\end{abstract}

\section{Introduction}

Twin-roll continuous casting is a proven technology for economical production of thin aluminum sheet directly from the melt [1, 2]. Many defects have been described and explained [3].The advantage of Twin-roll continuous casting is a shorter process route which combines casting and dynamic hot deformation down to a few mm gauge sheet in a single step.

In this paper, a process comprising of continuous casting and rolling of 5005 aluminum alloy with magnetostatic field is described. 5005 aluminum alloy sheet is manufactured by horizontal twin-roll continuous magnetostatic field casting technique. The aim of this work is to study the effect of magnetostatic field on the microstructure of 5005 aluminum alloy sheet.

\section{Experimental procedure}

Fig. 1 illustrates the horizontal twin-roll continuous casting process used in the experiment. It includes a source of molten metal that feeds into the space between a pair of counter-rotating, internally cooled rolls. A lubricating device is designed to smear lubricant on the roll surface.

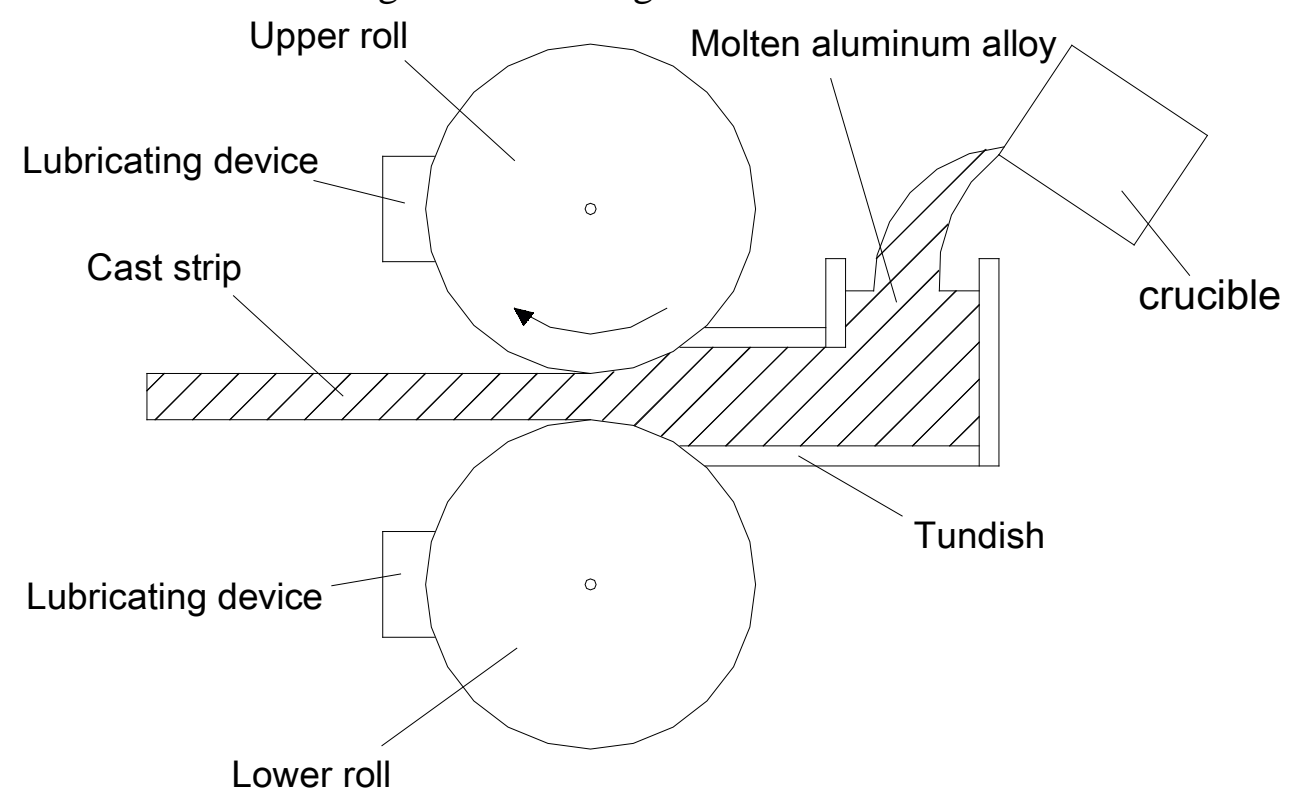

Fig. 1 Schematic illustration of a horizontal twin-roll continuous casting process 
5005 aluminum alloy was melted in graphite clay furnace using pure aluminum, pure magnesium, pure manganese and chromium preparation. Melt flowed to roll through aluminum silicate tundish after standing 20mins in furnace and was roll-cast by twin-roll caster. The roll-casting experiments included conventional roll-casting and magnetostatic field roll-casting. The pouring temperature of roll-casting process was $690{ }^{\circ} \mathrm{C}$. The roll casting speed was $1.5 \mathrm{~m} / \mathrm{min}$. The magnetostatic field intensity was $0.25 \mathrm{~T}$. Through several experiments, 5005 aluminum alloy sheet of $5 \mathrm{~mm}$ thickness with good surface quality and plate profile was obtained, such as Fig. 2.

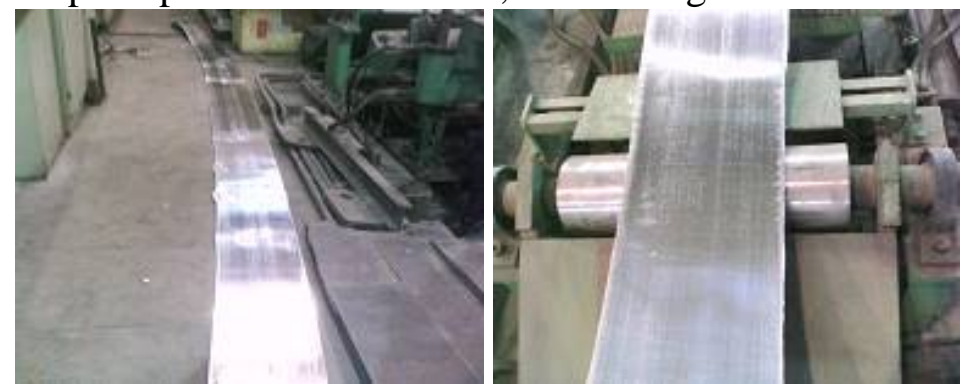

Fig. 25005 aluminum alloy sheet by roll-casting

Samples were selected from central part of conventional roll-casting sheet and magnetostatic field roll-casting sheet. Microstructures of cross section were observed through Leica optical microscope. Fig. 3 shows the procedure of aluminum alloy magnetostatic field roll-casting technique.

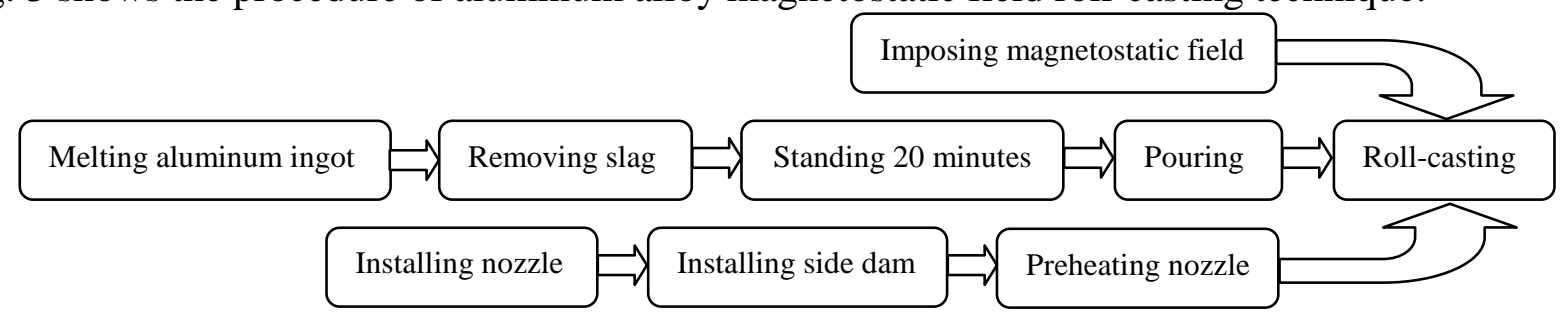

Fig. 3 The procedure of aluminum alloy magnetostatic field roll-casting technique

\section{Results and discussion}

During the roll-casting process of 5005 aluminum alloy, heat quantity of aluminum alloy melt in the cast-rolling zone is transferred to cooling water within roll core mostly through roll shell. Cooling ability of roll affects cooling rate and solidification rate of 5005 aluminum alloy melt directly. Too strong cooling and inadequate cooling can cause defects in roll-casting sheet. When roll-casing is underway, thin shell that is just solidified has a very small plastic deformation under the action of pressure of roll and the close contact between sheet and roll leads to nice thermal conductivity. So, metal melt cooled intensely in cast-rolling zone and cooling rate reaches $10^{2} \sim 10^{3} \mathrm{C} / \mathrm{s}$ that is higher two orders of magnitude than cooling rate of conventional water cooling semicontinuous casting. Therefore, the solidification of metal melt in roll-casting process is the rapid directional solidification and the solidification structure has necessarily characteristics which are rapid solidification and directional crystallization. The growth of crystal has very strong directivity.

Fig. 4 shows the transverse microstructures of 5005 aluminum alloy sheet under conventional roll-casting condition. Microstructures are composed of fine crystal zone, columnar crystal zone and equiaxed crystal zone. The thickness of fine crystal zone of upper layer and lower layer is relatively small and grains are fine and dense due to rapid solidification. The columnar crystal zone of transverse microstructures under conventional roll-casting condition is different with that of as-cast microstructures. The grain size of columnar crystal zone is comparatively uniform. Grains take shape grain groups and there are obvious boundary between grain groups. The equiaxed crystal zone is composed of large grains, dispersed small grains and developed dendrites and has severe segregation.

The transverse microstructures of 5005 aluminum alloy sheet under conventional roll-casting condition have characteristics of as-cast microstructures. The surface of sheet form fine crystal zone 
due to solidification under reaching $10^{2} \sim 10^{3} \mathrm{C} / \mathrm{s}$ cooling rate. The interlayer of sheet cools slower than surface. So, temperature gradient produces and that induces growth of columnar crystal. Columnar crystals grow along the direction of heat dissipation, thus forming columnar crystal zone with good orientation and large grains. The interlayer of sheet cools at last and cools slower. Heat dissipation has not directivity. So, grains grow along every direction, thus forming equiaxed crystal zone. However, during the process of roll-casting, the action of roll induces growth of grain along all direction, thus making growth of columnar crystals along different direction too. That causes that columnar crystal zone is composed of different sizes grain groups. Every grain group has relatively uniform grain size and directivity. The interlayer of sheet has a lot of dendrites formed along the direction of heat dissipation in the process of solidification. At the same time, there are impact action of metallic melt and crushing action of rolling deformation. So, some dendrites are broken up. Some small grains enter into metallic melt and grow into large grains. These large grains gather into grain groups commonly. Due to 5005 aluminum alloy has some alloying elements, there is constitutional undercooling. That makes alloying elements gathered in the interlayer. During solidification of interlayer, many compounds and precipitated phase are formed. They hinder the growth of grains and make grains fine and dispersed. So, microstructures of interlayer are composed of large grains, dispersed small grains and developed dendrites.

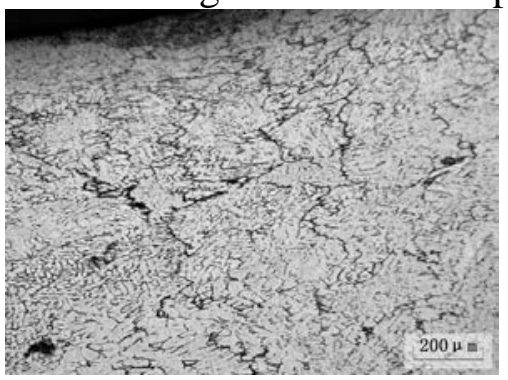

(a) Upper layer

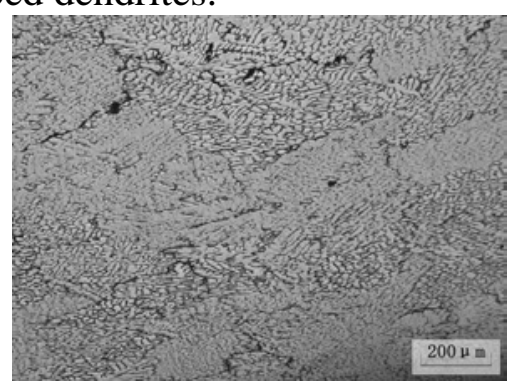

(b) Lower layer

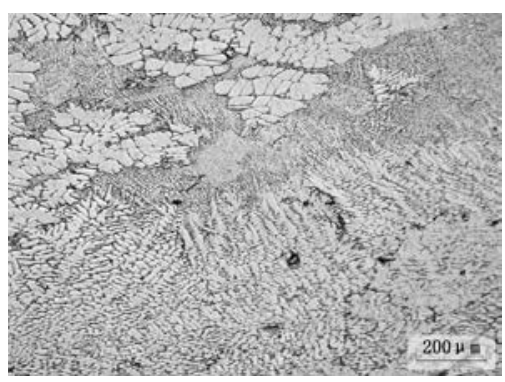

(c) Interlayer

Fig. 4 Conventional roll-casting microstructures

Fig. 5 shows the transverse microstructures of 5005 aluminum alloy sheet under magnetostatic field roll-casting condition. Compared with transverse microstructures under conventional roll-casting condition, they have not obvious as-cast characteristics. Surface grains are smaller and more uniform, and have not directivity. Microstructures of interlayer are imposed of large grains and fine dispersed grains. They have not dendrites basically. Alloying elements distribute uniformly. Segregation is not obvious. There is grain refining phenomenon.

Magnetostatic field imposed during the course of roll-casting process of aluminum alloy produces induced current due to existing natural convection and atomic vibration in melt. Induced current causes Lorentz force. Because of the effect of Lorentz force, solute particle does the helical orbital motion along the direction of magnetic line [4]. The disorder free motion of solute particle is in habited in some degree. Environment makes negative work for melt, which decreases melt' free energy and increases melt' diffusion activation energy to some extent. Grains' growth speed reduces. So, the purpose of refining grain is reached. The increment of diffusion difficulty induces the increment of contents of solute elements in grains, which can improve the strength of aluminum alloy substrate and reduce the harmful effects of brittle eutectic structure for alloy plasticity. So, the strength and formability of aluminum alloy improve [5]. It has been determined that the application of a magnetic field during the directional solidification of materials can significantly reduce convective flow in the melt $[6,7]$. Imposing magnetostatic field on the flow melt of solidification area frontier produces electromagnetic force due to electromagnetic induction. The electromagnetic force leads to electromagnetic brake [8], namely produces braking force for melt which flow speed is high, decreases the flow speed, homogenizes the flow speed of section, increases the nucleation rate of melt, and attains grain refinement [9]. 


\section{Conclusions}

The effect of magnetostatic field on microstructure of 5005 aluminum alloy sheet was investigated, and some results were obtained:

(1) The solidification of metal melt in roll-casting process is the rapid directional solidification;

(2) Imposing magnetostatic field on the roll-casting process can refine the microstructure of 5005 aluminum alloy roll-casting sheet.

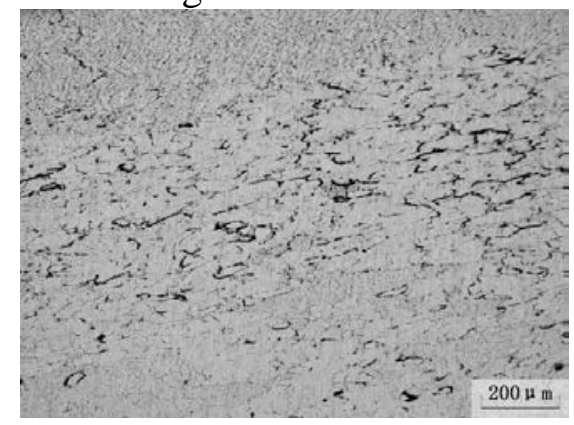

(a) Surface

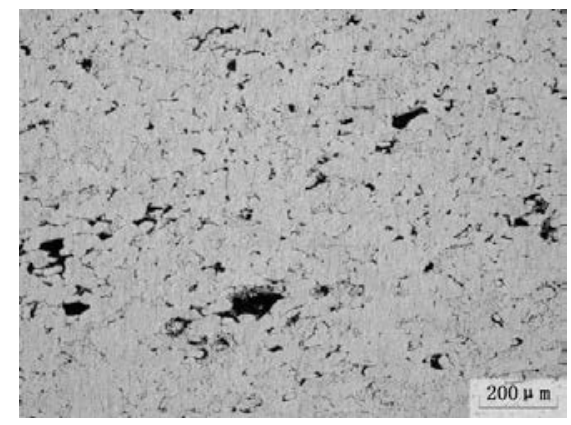

(b) Interlayer

Fig. 5 Magnetostatic field roll-casting microstructures

\section{References}

[1] R. Cook, P.G. Grocock, P.M. Thomas, D.V. Edmonds, and J.D. Hunt: Journal of Materials Processing Technology Vol. 55(1995), p.76-84.

[2] D.V. Edmonds: Journal of Materials Processing Technology Vol. 83(1998), p.1-13.

[3] M. Yun, S. Lokyer, and J.D. Hunt: Materials Science and Engineering A Vol. 280(2000), p.116-123.

[4] W.P. Bao, G.M. Xu, C.Y. Ban and J.Z. Cui: Acta Physica Sinica Vol. 53(2004), p.2024-2028, In Chinese.

[5] G.M. Xu, W.P. Bao, J.W. Zheng, Y.B. Zuo and J.Z. Cui: Chinese Journal of Rare Metals Vol. 28(2004), p.89-92, In Chinese.

[6] D.H. Matheson, M. Wargo, S. Motakef, D. Carlson, J. Nakos, A. Witt: J. Cryst. Growth Vol. 85(1987), p.557.

[7] G.D. Robertson, D. O’Connor: J. Cryst. Growth Vol. 76 (1986), p.100.

[8] G.W. Pen: Research Studies on Foundry Equipment Vol. 4(2007), p.47-49, In Chinese.

[9] G.M. Xu, W.P. Bao, J.Z. Cui and X.F. Gu: Journal of Northeastern University (Natural Science) Vol. 25(2004), p.48-50, In Chinese. 